\title{
A TEN-YEAR ANALYSIS OF CHANGES IN THE SENSITIVITY OF THE LEADING UROPATHOGEN TO ANTIBACTERIAL AGENTS IN CHILDREN WITH URINARY TRACT INFECTION IN THE NEPHROLOGY DEPARTMENT
}

DOI: 10.36740/WLek202007110

\author{
Tetiana V. Budnik, Tetiana B. Bevzenko \\ SHUPYK NATIONAL MEDICAL ACADEMY OF POSTGRADUATE EDUCATION NEPHROLOGY AND RRT DEPARTMENT, KYIV, UKRAINE
}

\begin{abstract}
The aim: To study the prevalence of ABR among children with UTI over the past 10 years, with an assessment of the sensitivity of $E$. Coli to common antibiotics in dynamics. Materials and methods: The study involved 1,044 children with UTI aged from 1 month to 18 years. Examination of patients and interpretation of the results was performed in accordance with the provisions of the Declaration of Helsinki of Human Rights. According to the design, the study included 3 comparison groups: Group 1 - children of the 2009 follow-up year $(n=337)$, Group 2 - of $2014(n=328)$ and Group 3 — of $2019(n=379)$.

Results: Escherichia coli is recognized as the leading uropathogen in all study groups: its percentage in Group 1 was 47 \% (158/337), in Group 2 — 64 \% (210/328) and in Group $3-66.5 \%$ (252/379). The prevalence of antibacterial resistance of E. coli strains and the high dynamics of its growth are shown. So the level of resistance of E. Coli in 2019 was $70 \pm 4.06 \%$ (176/252). This was $11 \%$ more compared to 2014 and $18.8 \%$ more compared to 2009. The percentage of multiresistant strains tended to increase and amounted to $28 \pm 9.97 \%$ (70/252) among patients with UTI and $40 \pm 9.12 \%$ (70/176) in the structure of resistance in 2019. The relative risk of ABR increased by 1.6 times in 2019 compared to $2014\left(\mathrm{RR}_{2019}=2.208 \pm 0.207[1.473 ; 3.310], \mathrm{p}<0.05\right.$ vs $\left.\mathrm{RR}_{2014}=1.375 \pm 0.209[0.913 ; 2.063]\right)$ and by 3 times compared to $2009\left(\mathrm{RR}_{2009}=0.727 \pm 0.209\right.$ [0.483;1.095]). Ampicillin and amoxicillin showed an equally low sensitivity level $(3.5 \pm 32.14 \%(9 / 252))$. Only every second child confirmed sensitivity to cefuroxime (53.6 \pm 5.76 (135/252)). Ceftazidime and ciprofloxacin showed a relatively high sensitivity level $-77.4 \pm 3.34$ (195/252) and $83 \pm 2.81$ (209/252), and at the same time the rapidly growing resistance rates — almost twice as high over the past 5 years. Furazidin $K$ showed a high sensitivity level of $85.7 \pm 2.53 \%$ (216/252), the lowest level of overall resistance of $14.3 \pm 15.15 \%$ (36/252) and a slow rate of its formation. An unfavourable prognosis of an increase in the relative risk of ABR by 2.9-3.7 times in the next 5-10 years was determined among patients with UTI, provided that the existing diagnostic and treatment approaches are maintained.

Conclusions: The study results are important for understanding the clinical decision on the benefits of antibacterial therapy and optimizing its empirical choice for a patient with UTI.
\end{abstract}

KEY WORDS: urinary tract infection, children, E. Coli, antibiotic resistance

Wiad Lek. 2020;73(7):1360-1364

\section{INTRODUCTION}

Selection of drug-resistant strains of pathogens is an integral part of modern antibacterial therapy [1]. Antimicrobial resistance is becoming a big risk to the global health of mankind [2].

Urinary tract infection (UTI), as one of the most common bacterial infections in children with an empirical antibiotic treatment strategy, is of particular multifaceted relevance [3]. Escherichia coli in childhood plays an important role as an infectious factor, as it is the cause of more than $80 \%$ of all UTIs, bacteremia, foodborne infections, meningitis in newborns and other life-threatening conditions [4].

Recent studies have shown that up to half of E. Coli culture samples in children with urinary tract infections (UTI) are resistant to common antibiotics [5]. Researchers from the University of Bristol and Imperial College London studied antibiotic resistance in UTI caused by Escherichia coli and showed a growing level of its resistance to $\beta$-lactam antibacterial agents (ampicillin, amoxicillin, including protected by clavulanic acid) [6]. In other developed countries, a third of E. Coli samples were resistant to co-trimoxazole, and a quarter - to trimethoprim. In developing countries, resistance was even higher, probably due to the availability of overthe-counter antibiotics, according to the authors $[7,8]$. Researchers point to the broad regular prescription of antibiotics by primary care physicians, which poses a high risk of resistance in children, which can persist up to 6-12 months after treatment $[5,9]$.

So, on the one hand, children receive a disproportionately large number of antibiotics compared to other segments of the population, on the other hand, they are more vulnerable to immediate and long-term complications, such as renal scarring and renal impairment in inadequate treatment of UTI [10]. Constant monitoring of local microbial sensitivity is an absolute necessity for the correct empirical choice of antibiotic. 
Table I. Dynamics of E. coli sensitivity in patients with UTI for the period 2009 - 2019.

\begin{tabular}{|c|c|c|c|c|}
\hline \multirow[b]{2}{*}{ Antibiotics } & \multirow{2}{*}{$\begin{array}{c}\text { Strains } \\
\text { E.coli }\end{array}$} & \multicolumn{3}{|c|}{ Years } \\
\hline & & $\begin{array}{c}2009 \\
\% \pm 95 \% \text { Cl, (abs.) }\end{array}$ & $\begin{array}{c}2014 \\
\% \pm 95 \% \mathrm{Cl}, \text { (abs.) }\end{array}$ & $\begin{array}{c}2019 \\
\% \pm 95 \% \mathrm{Cl} \text {, (abs.) }\end{array}$ \\
\hline \multirow{3}{*}{ Ampicillin } & $S$ & $20 \pm 15,06(34 / 168)$ & $\begin{array}{c}30,5 \pm 10,24^{*} \\
(64 / 210)\end{array}$ & $\begin{array}{c}3,5 \pm 32,14^{*} \\
(9 / 252)\end{array}$ \\
\hline & MR & $\begin{array}{c}28,6 \pm 11,99 \\
(48 / 168)\end{array}$ & $\begin{array}{c}29,5 \pm 10,47 \# \\
(62 / 210)\end{array}$ & $90,5 \pm 2,01 *(228 / 252)$ \\
\hline & $\mathrm{R}$ & $\begin{array}{r}51,4 \pm 7,41 \\
(86 / 168) \\
\end{array}$ & $\begin{array}{l}40 \pm 8,3 \# \\
(84 / 210)\end{array}$ & $\begin{array}{r}6 \pm 24,59 * \\
(15 / 252) \\
\end{array}$ \\
\hline \multirow{3}{*}{ Amoxicillin } & $S$ & $\begin{array}{c}23,2 \pm 13,79 \\
(39 / 168)\end{array}$ & $\begin{array}{c}4,3 \pm 32,04^{*} \\
(9 / 210)\end{array}$ & $\begin{array}{c}3,5 \pm 32,14^{*} \\
(9 / 252)\end{array}$ \\
\hline & MR & $\begin{array}{c}32,1 \pm 11,17 \\
(53 / 168)\end{array}$ & $\begin{array}{c}36,7 \pm 8,91 \# \\
(77 / 210)\end{array}$ & $\begin{array}{c}26,6 \pm 10,28 \# \\
(67 / 252)\end{array}$ \\
\hline & $\mathrm{R}$ & $\begin{array}{c}44,7 \pm 8,34 \\
(76 / 168)\end{array}$ & $\begin{array}{l}59 \pm 5,65^{*} \\
(124 / 210)\end{array}$ & $\begin{array}{l}70 \pm 4,06^{*} \\
(176 / 252)\end{array}$ \\
\hline \multirow{3}{*}{ Cefuroxime } & $S$ & $\begin{array}{l}63,7 \pm 5,73 \\
(107 / 168) \\
\end{array}$ & $\begin{array}{c}56,2 \pm 5,99 \# \\
(118 / 210)\end{array}$ & $\begin{array}{c}53,6 \pm 5,76^{*} \\
(135 / 252)\end{array}$ \\
\hline & MR & $\begin{array}{c}14,2 \pm 18,58 \\
(24 / 168)\end{array}$ & $\begin{array}{c}34,8 \pm 9,29^{*} \\
(73 / 210)\end{array}$ & $\begin{array}{c}27,4 \pm 10,07^{*} \\
(69 / 252)\end{array}$ \\
\hline & $\mathrm{R}$ & $\begin{array}{c}22,1 \pm 14,27 \\
(37 / 168)\end{array}$ & $\begin{array}{l}9 \pm 21,49^{*} \\
(19 / 210)\end{array}$ & $\begin{array}{c}19 \pm 12,75 \# \\
(48 / 252)\end{array}$ \\
\hline \multirow{3}{*}{ Ceftazidime } & $S$ & $89,3 \pm 2,63(150 / 168)$ & $\begin{array}{c}54,8 \pm 6,16^{*} \\
(115 / 210)\end{array}$ & $\begin{array}{c}77,4 \pm 3,34^{*} \\
(195 / 252)\end{array}$ \\
\hline & MR & $\begin{array}{c}6,6 \pm 28,65 \\
(11 / 168)\end{array}$ & $\begin{array}{c}38,1 \pm 8,64^{*} \\
(80 / 210)\end{array}$ & $\begin{array}{c}8,3 \pm 20,52 \# \\
(21 / 252)\end{array}$ \\
\hline & $\mathrm{R}$ & $\begin{array}{c}2,1 \pm 48,56 \\
(4 / 168)\end{array}$ & $\begin{array}{c}7,1 \pm 24,44 \# \\
(15 / 210)\end{array}$ & $\begin{array}{c}14,3 \pm 15,15^{*} \\
(36 / 252)\end{array}$ \\
\hline \multirow{3}{*}{ Ciprofloxacin } & $S$ & $\begin{array}{l}88,1 \pm 2,79 \\
(148 / 168) \\
\end{array}$ & $78,6 \pm 3,54 \#(165 / 210)$ & $\begin{array}{l}83 \pm 2,81 \# \\
(209 / 252)\end{array}$ \\
\hline & MR & $\begin{array}{r}9,8 \pm 23,37 \\
(16 / 168)\end{array}$ & $\begin{array}{c}15,7 \pm 15,7 \# \\
(33 / 210)\end{array}$ & $\begin{array}{r}6 \pm 24,59 \# \\
(15 / 252)\end{array}$ \\
\hline & $\mathrm{R}$ & $\begin{array}{c}2,1 \pm 48,56 \\
(4 / 168)\end{array}$ & $\begin{array}{c}5,7 \pm 27,54 \# \\
(12 / 210)\end{array}$ & $\begin{array}{r}11 \pm 17,5^{*} \\
(28 / 252)\end{array}$ \\
\hline \multirow{3}{*}{ Furazidine K } & $S$ & $\begin{array}{l}84,5 \pm 3,24 \\
(142 / 168)\end{array}$ & $\begin{array}{c}66,7 \pm 4,79^{*} \\
(140 / 210)\end{array}$ & $85,7 \pm 2,53 \#(216 / 252)$ \\
\hline & MR & $\begin{array}{c}10,7 \pm 21,89 \\
(18 / 168) \\
\end{array}$ & $\begin{array}{c}27,6 \pm 10,97^{*} \\
(58 / 210)\end{array}$ & $\begin{array}{c}6,3 \pm 23,76 \# \\
(16 / 252)\end{array}$ \\
\hline & $\mathrm{R}$ & $\begin{array}{c}4,8 \pm 33,91 \\
(8 / 168)\end{array}$ & $\begin{array}{c}5,7 \pm 27,54 \# \\
(12 / 210)\end{array}$ & $\begin{array}{r}8 \pm 21,07 \# \\
(20 / 252)\end{array}$ \\
\hline
\end{tabular}

Notes. S - sensitive strains, MR — moderately resistant, $\mathrm{R}$ - resistant, $\mathrm{Cl}$ - confidence interval, $\mathrm{p}$ - statistical significance according to Pearson's chi-square test, compared to Group $1,{ }^{*}-p<0.05$, \# $-p<0.05$.

\section{THE AIM}

The aim was to study the prevalence of antibiotic resistance among children with UTI over the past 10 years, with an assessment of the sensitivity of $E$. Coli to common antibiotics in dynamics.

\section{MATERIALS AND METHODS}

The study involved 1,044 children with UTI aged from 1 month to 18 years, who were treated in the Paediatric Nephrology Unit of Kyiv City Children's Clinical Hospital No. 1 in 2009, 2014 and 2019 (interval up to 5 years).
According to the design, the study included $3 \mathrm{com}$ parison groups: Group 1 - children of the 2009 follow-up year $(\mathrm{n}=337)$, Group 2 - of $2014(\mathrm{n}=328)$ and Group 3 - of $2019(n=379)$. The examination of patients and the management of the obtained data were consistent with the provisions of the Declaration of Helsinki of Human Rights.

Diagnosis of diseases was performed according to the unified clinical protocol No. 627 of the $\mathrm{MOH}$ of Ukraine of November 3, 2008 "On approval of the treatment protocol for children with urinary tract infections and 
Table II. Dynamics of E. coli resistance in patients with UTI for 2009 - 2019

\begin{tabular}{|c|c|c|c|}
\hline \multirow{2}{*}{$\begin{array}{c}\text { Strains } \\
\text { E.coli }\end{array}$} & \multicolumn{3}{|c|}{ Years } \\
\hline & $\begin{array}{c}2009 \\
\% \pm 95 \% \text { Cl, (abs.) }\end{array}$ & $\begin{array}{c}2014 \\
\% \pm 95 \% \mathrm{Cl} \text {, (abs.) }\end{array}$ & $\begin{array}{c}2019 \\
\% \pm 95 \% \mathrm{Cl} \text {, (abs.) }\end{array}$ \\
\hline Resistant & $51,2 \pm 7,41(86 / 168)$ & $59 \pm 5,65 \#(124 / 210)$ & $70 \pm 4,06 *(176 / 252)$ \\
\hline Monoresistant & $25 \pm 13,13(42 / 168)$ & $32,4 \pm 9,8 *(68 / 210)$ & $42 \pm 7,26 *(106 / 252)$ \\
\hline Multiresistant & $26,2 \pm 12,73(44 / 168)$ & $26,6 \pm 11,24 \#(56 / 210)$ & $28 \pm 9,97 \#(70 / 252)$ \\
\hline
\end{tabular}

Notes. $p$ - statistical significance according to Pearson's chi-square test, compared to Group $1,{ }^{*}-p<0.05, \#-p<0.05$.

tubulointerstitial nephritis". The generally accepted diagnostic methods for nephrological patients were applied. Among them: complete blood count and urinalysis, liver and renal tests with calculation of glomerular filtration rate (GFR), proteinogram, measurement of C-reactive protein, Nechiporenko test and Zimnitsky test, bacterial urine culture to determine the pathogen and its sensitivity using the disc dispersion method (DDM), ultrasound of the kidneys and bladder, voiding cystourethrography and excretory urography, if necessary.

Assessment of the distribution of the studied parameters using Pearson's chi-squared test confirmed the normal distribution. Statistical hypotheses were tested using the chi-square goodness of fit test. For fractional values, the $95 \%$ confidence interval (CI) of the parameter distribution was calculated. The absolute and relative probability frequencies were calculated by the odds ratio (OR) with the calculation of the standard error under condition of $95 \%$ CI. The threshold value for statistical significance was set at $\leq 0.05[11]$.

Mathematical and statistical calculations were obtained using Microsoft Excel programs (Microsoft Office 2013 Professional Plus, license agreement (EULAID:O15_RTM_ VL.1_RTM_RU) and STATISTICA 13.0 (StatSoftInc., Serial No. ZZS9990000099100363DEMO-L).

\section{RESULTS}

The leading uropathogen in all study groups was E. coli with a tendency to increase its specific gravity every 5 years. In Group 1 of patients (2009), the percentage of E. Coli was $47 \%(158 / 337)$, in Group 2 (2014) - $64 \%$ (210/328) and in Group 3 (2019) - 66.5 \% (252/379).

The dynamics of changes in the sensitivity of Escherichia coli to a common range of antibiotics over the past 10 years with the statistical forecast of the distribution of parameters is shown in Table I. Among the studied classes of antibiotics there are representatives of $\beta$-lactams (ampicillin, amoxicillin, cefuroxime, ceftazidime, ciprofloxacin) and representative of nitrofurans (furazidin K).

As can be seen from Table I, in 2019, the sensitivity of E. Coli (in percentage of cases) to ampicillin and amoxicillin was equally low and amounted to $3.5 \pm 32.14$ (9/252), to cefuroxime $-53.6 \pm 5.76(135 / 252)$, to ceftazidime $77.4 \pm 3.34(195 / 252)$, to ciprofloxacin $-83 \pm 2.81$ $(209 / 252)$ and to furazidin $\mathrm{K}-85.7 \pm 2.53$ (216/252). In turn, resistance values were as follows: to ampicillin -
$6 \pm 24.5(15 / 252)$, to amoxicillin $-70 \pm 4.06(176 / 252)$, to cefuroxime $-19 \pm 12.75$ (48/252), to ceftazidime $14.3 \pm 15.15(36 / 252)$ and to furazidin $\mathrm{K}-8 \pm 21.07$ (20/252). Moderately resistant strains to ampicillin $90.5 \pm 2.01(228 / 252)$, to amoxicillin $-26.6 \pm 10.28$ $(67 / 252)$, to cefuroxime $-27.4 \pm 10.07(69 / 252)$, to ceftazidime $-8.3 \pm 20.52(21 / 252)$, to ciprofloxacin $6 \pm 24.59(15 / 252)$, to furazidin $\mathrm{K}-6.3 \pm 23.76(16 / 252)$ were found.

Assessment of the prevalence of resistant Escherichia coli with the calculation of the percentage of monoresistant and multiresistant strains and the dynamics of changes every 5 years is shown in Table II.

The data in Table II showed that the overall level of resistant E. Coli strains at $95 \%$ CI in 2009 was $51.2 \pm 7.41$ $(86 / 168)$, in $2014-59 \pm 5.65(124 / 210)$ and in $2019-$ $70 \pm 4.06(176 / 252)$. Moreover, in 2019, the monoresistant conditions in the total sample of UTI patients were $42 \pm 7.26(106 / 252)$ cases, multiresistant $-28 \pm 9.97$ (70/252).

The results of assessing the relative risk (RR) of resistance formation in patients with UTI during the indicated follow-up periods and its mathematical prognosis for the next 10 years are shown in Fig. 1.

As can be seen from the graph, the relative risk of antibiotic resistance in 2009 was $\mathrm{RR}=0.727 \pm 0.209$ [0.483; $1.095]$, in $2014-\mathrm{RR}=1.375 \pm 0.209$ [0.913/2.063], $\mathrm{p}>0.05$ and in $2019-\mathrm{RR}=2.208 \pm 0.207$ [1.473;3.310], $\mathrm{p}<0.05$. According to the equation of the trend line, the relative risk of E. Coli resistance in 2024 will be $\mathrm{RR}=0.7405^{\star} 4-0.0443=2.918$, and in $2029-\mathrm{RR}=3.658$ with a high statistical significance $\left(R^{2}=0.9948\right)$.

\section{DISCUSSION}

The international community of nephrologists, urologists, infectious disease specialists (IDSA, EAU, AUA) identified the level of antibiotic resistance in the range of 10-20\% of strains, within which the empirical prescription of an antibacterial drug is possible [12]. If the culture test results are available, only the drugs with the sensitivity of microorganisms to these drugs should be prescribed [13]. The use of drugs with moderate resistance of the strains is also clinically justified, since it may not lead to patient recovery but may contribute to the recurrence or persistence of infection, the formation of resistance of microorganisms and other complications [14]. 


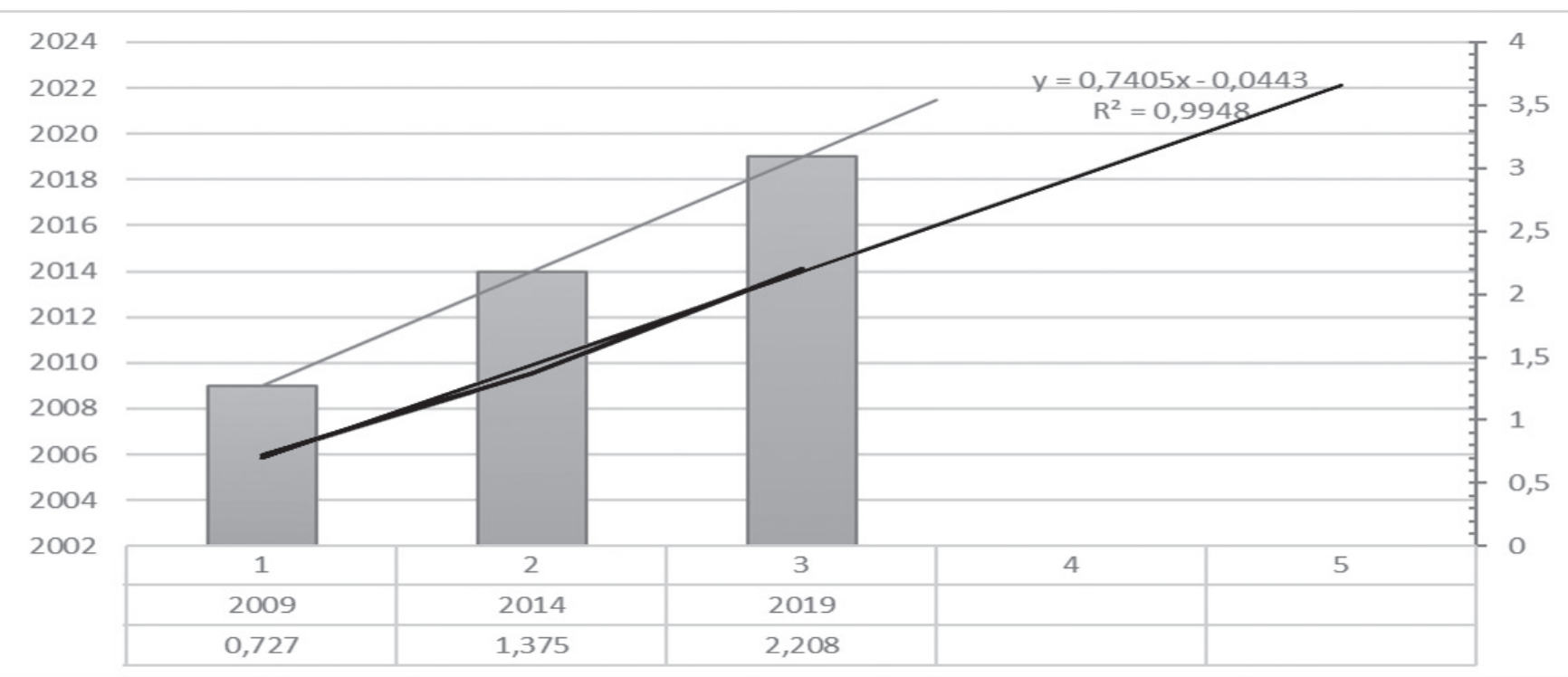

Fig. 1. Assessment and prognosis of the relative risk (RR) of antibiotic resistance in children with UTI

Notes. $y=0.7405 x-0.0443$ is the equation of the trend line to calculate the prognostic value in the following periods, where $x$ is the number of the period; $\mathrm{R}^{2}$ is coefficient of determination.

The results of our study showed that neither ampicillin nor amoxicillin can be the drugs of empirical choice in the treatment of UTI in children, which coincided with the studies of other authors [15]. But we also noted that cefuroxime cannot be a first-line drug without a culture test, since only every second child confirmed sensitivity to it $(53.6 \pm 5.76(135 / 252))$, while the level of overall resistance (R strains + MR strains) was $46.4 \pm 6.64(117 / 252)$. Relatively high sensitivity was shown for ceftazidime and ciprofloxacin in $2019(77.4 \pm 3.34(195 / 252)$ and $83 \pm 2.81$ (209/252), respectively), while resistance to them grew quite rapidly - almost doubled in the last 5 years. Thus, overall resistance $(\mathrm{R}+\mathrm{MR})$ in 2019 for ceftazidime was $22.6 \pm 11.44(57 / 252)$, for ciprofloxacin $-17.0 \pm 13.64$ (43/252). A high sensitivity of $85.7 \pm 2.53(216 / 252)$ was determined for furazidin $\mathrm{K}$ as the representative of nitrofurans. With the best value of the overall resistance of strains in $2019-14.3 \pm 15.15(36 / 252)$ and the relatively slow formation of resistance. The value increase by 1.7 times over the past 10 years.

We found that the resistance level of E. Coli among children with UTIs has especially grown over the past 5 years, and compared to the 10-year period, the number of resistant strains has increased by $20 \%$. The percentage of multiresistant strains also tended to increase so that in 2019 almost every second child with resistance had multiresistant strains $40 \pm 9.12$ (70/176). We statistically evaluated and determined the current adverse trends of ABR according to the relative risk analysis. In 2019 it increased by 1.6 times compared to $2014\left(\mathrm{RR}_{2019}=2.208 \pm 0.207\right.$ [1.473;3.310], $\mathrm{p}<0.05$ vs $\left.\mathrm{RR}_{2014}=1.375 \pm 0.209[0.913 ; 2.063]\right)$ and by 3 times compared to $2009\left(\mathrm{RR}_{2009}=0.727 \pm 0.209[0.483 ; 1.095]\right)$. The mathematical equation of the trend line allowed us to determine the prognosis for $A B R$ for the next 5-10 years if the existing diagnostic and therapeutic tactics of UTI are maintained. It was found that the relative risk of $A B R$ progressively increased by 2.9-3.7 times. For comparison, $\mathrm{RR}_{2009}=0.727 \pm 0.209$ [0.483; 1.095] and $\mathrm{RR}_{2029}=3.658$ with $\mathrm{R}^{2} \stackrel{2009}{=} 0.9948$.

The study results are important for the management of paediatric UTI, both in primary health care and for optimal clinical decisions made by highly specialized doctors. Doctors should consider the effect of any use of antibiotics on further antimicrobial resistance and avoid their inadequate use. They should also adhere to data on local sensitivity and national recommendations, when the prescription of an antibacterial agent is indicated.

\section{CONCLUSIONS}

1. The antibacterial resistance of $E$. Coli strains is common among children with UTI and has high growth dynamics.

2. The resistance level of $E$. Coli was $70 \pm 4.06 \%(176 / 252)$, which is $11 \%$ more compared to 2014 and $18.8 \%$ more compared to 2009 .

3. The percentage of multiresistant $E$. Coli strains tended to increase and amounted to $28 \pm 9.97 \%(70 / 252)$ among patients with UTI and $40 \pm 9.12 \%(70 / 176)$ in the structure of resistance in 2019.

4. The relative risk of $A B R$ in 2019 increased by 1.6 times compared to 2014 (RR2019 $=2.208 \pm 0.207$ [1.473;3.310], $\mathrm{p}<0.05$ vs RR2014 = $1.375 \pm 0.209$ $[0.913 ; 2.063])$ and by 3 times compared to 2009 $(\mathrm{RR} 2009=0.727 \pm 0.209[0.483 ; 1.095])$.

5. Ampicillin and amoxicillin cannot be the empirical choice in the treatment of UTI, because they show an equally low sensitivity $(3.5 \pm 32.14 \%(9 / 252))$.

6. Cefuroxime cannot be a first-line drug without a culture test, since only every second child confirmed sensitivity to it $(53.6 \pm 5.76(135 / 252))$. 
7. Ceftazidime and ciprofloxacin showed a relatively high sensitivity level $-77.4 \pm 3.34(195 / 252)$ and $83 \pm 2.81$ (209/252), respectively. At the same time, the rapidly growing resistance was recorded - almost doubled over the past 5 years.

8. Furazidin $\mathrm{K}$ showed a high sensitivity level of $85.7 \pm 2.53 \%(216 / 252)$, the lowest level of overall resistance of $14.3 \pm 15.15 \%(36 / 252)$ and a slow rate of its formation.

9. The prognosis for the relative risk of $A B R$ for the next 5-10 years is determined as an increase by 2.9-3.7 times if the existing diagnostic and therapeutic tactics of UTI are maintained.

\section{REFERENCES}

1. Bryce A., Hay A.D., Lane I.F., Thornton H.V., Wootton M., Costelloe C. Global prevalence of antibiotic resistance in paediatric urinary tract infections caused by Escherichia coli and association with routine use of antibiotics in primary care: systematic review and metaanalysis. BMJ. 2016;15: 939-945.

2. Alberici l., Bayazit A.K., Drozdz D.et al. Pathogens causing urinary tract infections in infants: a European overview by the ESCAPE study group. Eur J Pediatr. 2015;174: 783-790.

3. Lee Y.K., Lee H.J., Kim J.M., Kang J.M, et al. The Antibiotic Resistance Pattern of Gram-Negative Bacteria in Children Younger Than 24 Months with a Urinary Tract Infection: A Retrospective Single-Center Study over 15 Consecutive Years. Child Kidney Dis. 2015;19: 148-53.

4. Kim S.H., Lee J.A. The impact of the antibiotic burden on the selection of its resistance among gram negative bacteria isolated from children. Pediatr Infect Vaccine. 2015;22: 178-85.

5. Bryce A., Costelloe C., Hawcroft C. et al. Faecal carriage of antibiotic resistant Escherichia coli in asymptomatic children and associations with primary care antibiotic prescribing: a systematic review and metaanalysis. BMC Infect Dis 2016;16: 359.

6. Ahn D.H., Kim K.W., Cho H.K., Tchah H., Jeon I.S., Ryoo E. et al. Febrile Urinary Tract Infections Caused by Community-Acquired ExtendedSpectrum beta-Lactamase-Producing and-Nonproducing Bacteria: A Comparative Study. Pediatr Infect Vaccine. 2015;22: 29-35.

7. Whiteside S.A., Razvi H., Dave S., Reid G., Burton J.P. The microbiome of the urinary tract - a role beyond infection. Nat Rev Urol. 2015 Feb; 12(2): $81-90$.

8. Aragón I.M., Herrera-Imbroda B., Queipo-Ortuño M.I., Castillo E., Del Moral J.S., Gómez-Millán J. et al The Urinary Tract Microbiome in Health and Disease. Eur Urol Focus. 2018 Jan; 4(1): 128-138.

9. Magistro G., Stief C.G. The Urinary Tract Microbiome: The Answer to All Our Open Questions? Eur Urol Focus. 2019 Jan; 5(1): 36-38.

10. Wolfe A.J., Brubaker L. Urobiome updates advances in urinary microbiome research. Nat Rev Urol. 2019 Feb; 16(2): 73-74.
11. Martin Bland An introduction to medical statistics: Oxford University Press, 4th edition. 2015; 464 pp. ISBN 978-0-19-958992-0

12. Brubaker L., Wolfe A.J. Microbiota in 2016: Associating infection and incontinence with the female urinary microbiota. Nature Reviews Urology. 2017 Feb; 14(2):72-74.

13. Lee S.J. Recent advances in managing lower urinary tract infections. F1000Res. 2018; 7: F1000 Faculty Rev-1964. doi: 10.12688/ f1000research.16245.1

14. Mantadakis E., Vouloumanou E.K., Panopoulou M. et al. Susceptibility patterns of uropathogens identified in hospitalised children with communityacquired urinary tract infections in Thrace, Greece. J Glob Antimicrob Resist 2015; 3: 85-90.

15. Calevo M.G., Losurdo G., Piaggio G. et al. Resistance to oral antibiotics in 4569 Gramnegative rods isolated. Eur J Pediatr 2016; 175: 1219-25.

The work was performed as part of the research work of the Research Department "Improvement and development of methods for treating patients with chronic kidney disease", 0114U002216, time for completion 2013-2018 and "Studying the effects of hypouricemic therapy in patients with chronic kidney disease and justifying appropriate treatment", time for completion 2019-2023. There were no grants or other sources of funding.

\section{ORCID and contributionship:}

Tetiana V. Budnik: 0000-0003-3956-3903 ${ }^{A, B, C, D}$

Tetiana B. Bevzenko: 0000-0001-9042-6651 ${ }^{B}$

\section{Conflict of interest:}

The Authors declare no conflict of interest.

\section{CORRESPONDING AUTHOR Tetiana V. Budnik}

Shupyk National Medical Academy of Postgraduate Education 9 Dorogozhitskaya st., 04112 Kyiv, Ukraine

tel: +380506990221

e-mail:budniktania8@gmail.com

Received: 20.02 .2020

Accepted: 17.06 .2020

A - Work concept and design, B - Data collection and analysis, C - Responsibility for statistical analysis, D-Writing the article, $\mathbf{E}$-Critical review, $\mathbf{F}$ - Final approval of the article 